\title{
Article
}

\section{The Influence of Specific Bioactive Collagen Peptides on Body Composition and Muscle Strength in Middle-Aged, Untrained Men: A Randomized Controlled Trial}

\author{
Denise Zdzieblik $^{1}\left(\mathbb{D}\right.$, , Patrick Jendricke ${ }^{1, *(\mathbb{D}}$, Steffen Oesser ${ }^{2}$, Albert Gollhofer $^{1}$ and Daniel König ${ }^{3,4}$ \\ 1 Department for Nutrition, Institute for Sports and Sports Science, University of Freiburg, Schwarzwaldstr 175, \\ 79117 Freiburg, Germany; denise.zdzieblik@cri-mail.org (D.Z.); ag@sport.uni-freiburg.de (A.G.) \\ 2 CRI, Collagen Research Institute, Schauenburgerstr 116, 24118 Kiel, Germany; steffen.oesser@cri-mail.org \\ 3 Centre of Sports Science, Department for Nutrition, Exercise and Health, University of Vienna, \\ Auf der Schmelz 6, 1150 Vienna, Austria; Daniel.Koenig@univie.ac.at \\ 4 Department for Nutrition, Exercise and Health, Faculty of Life Sciences, University of Vienna, \\ Althanstrasse 14, 1090 Vienna, Austria \\ * Correspondence: Patrick.Jendricke@sport.uni-freiburg.de; Tel.: +49-761-20354240
}

\section{check for} updates

Citation: Zdzieblik, D.; Jendricke, P.; Oesser, S.; Gollhofer, A.; König, D. The Influence of Specific Bioactive Collagen Peptides on Body Composition and Muscle Strength in Middle-Aged, Untrained Men: A Randomized Controlled Trial. Int. J. Environ. Res. Public Health 2021, 18 , 4837. https://doi.org/10.3390/ ijerph18094837

Academic Editor: Michal Wilk

Received: 13 April 2021

Accepted: 29 April 2021

Published: 30 April 2021

Publisher's Note: MDPI stays neutral with regard to jurisdictional claims in published maps and institutional affiliations.

Copyright: (C) 2021 by the authors Licensee MDPI, Basel, Switzerland. This article is an open access article distributed under the terms and conditions of the Creative Commons Attribution (CC BY) license (https:// creativecommons.org/licenses/by/ $4.0 /)$.
Abstract: It has been shown that specific collagen peptides combined with resistance training (RT) improves body composition and muscle strength in elderly sarcopenic men. The main purpose of this RCT study was to investigate the efficacy of the identical specific collagen peptides combined with RT on body composition and muscle strength in middle-aged, untrained men. Furthermore, in the exploratory part of the study, these results were compared with another group that had received whey protein in addition to the RT. Ninety-seven men completed this study and participated in a 12-week RT program. They ingested $15 \mathrm{~g}$ of specific collagen peptides $(n=30 ; C P-G)$, placebo $(n=31 ; P-G)$, or whey protein $(n=36 ; W P-G)$ daily. Changes in fat free mass and fat mass were determined by dual-energy $\mathrm{X}$-ray absorptiometry (DXA), and isometric leg strength was measured. All participants had significantly $(p<0.01)$ improved levels in fat free mass $(\triangle \mathrm{CP}-\mathrm{G}=3.42 \pm 2.54 \mathrm{~kg} ; \Delta \mathrm{P}-\mathrm{G}=1.83 \pm 2.09 \mathrm{~kg} ; \Delta \mathrm{WP}-\mathrm{G}=2.27 \pm 2.56 \mathrm{~kg})$, fat mass $(\Delta \mathrm{CP}-\mathrm{G}=-5.28 \pm 3.19 \mathrm{~kg} ; \Delta \mathrm{P}-\mathrm{G}=-3.39 \pm 3.13 \mathrm{~kg} ; \Delta \mathrm{WP}-\mathrm{G}=-4.08 \pm 2.80 \mathrm{~kg})$ and leg strength $(\Delta \mathrm{CP}-\mathrm{G}=163 \pm 189 \mathrm{~N} ; \Delta \mathrm{P}-\mathrm{G}=100 \pm 154 \mathrm{~N} ; \Delta \mathrm{WP}-\mathrm{G}=120 \pm 233 \mathrm{~N})$. The main analysis revealed a statistically significantly higher increase in fat free mass $(p=0.010)$ and decrease in fat mass $(p=0.023)$ in the $\mathrm{CP}-\mathrm{G}$ compared with the P-G. The exploratory analysis showed no statistically significant differences between WP-G and CP-G or P-G, regarding changes of fat free mass and fat mass. In conclusion, specific collagen peptide supplementation combined with RT was associated with a significantly greater increase in fat free mass and a decrease in fat mass compared with placebo. RT combined with whey protein also had a positive impact on body composition, but the respective effects were more pronounced following the specific collagen peptide administration.

Keywords: collagen peptides; whey protein; resistance training; DXA; body composition; muscle strength

\section{Introduction}

Characteristics of the aging process include a decrease in muscle mass, strength and functionality. In general, muscle strength and function are assumed to decrease from an average age of about 40 [1,2]. This, together with an increase in fat mass, is often accompanied by orthopedic complaints and an impairment of cardiometabolic risk factors such as increased weight, waist circumference and triglyceride levels, reduced HDLcholesterol or impaired glucose tolerance [3]. The combination of reduced muscle mass with increased fat mass is defined as sarcopenic obesity, and is associated with a higher mortality risk than sarcopenia or adiposity alone [4]. Interventions aimed at increasing 
muscle mass and reducing fat mass may therefore help prevent the onset or severity of sarcopenia-related diseases.

An imbalance in caloric intake and energy expenditure contributes to an increase in the number of overweight people or those with obesity. Various studies have shown that regular physical activity, in particular resistance exercise, improves body composition and muscle function $[5,6]$. Current evidence suggests that the addition of protein may support the effect of strength training on muscle protein synthesis [7]. Dietary proteins are thought to stimulate muscle growth at a cellular level mainly through their content of branchedchain amino acids (BCAA), particularly leucine, via the mTOR-pathway [8]. Nonetheless, the beneficial effect of protein intake-especially regarding the optimal type and amount in different populations-on muscle mass following RT is still under discussion. The current recommendation for the promotion of muscle mass is 1-3 $\mathrm{g}$ of leucine or 10-12 $\mathrm{g}$ of essential amino acids in younger adults [9]. However, collagen peptides contain only a small percentage of leucine $(0.4 \mathrm{~g} / 15 \mathrm{~g})$ [10]. In addition, the total amount of essential amino acids is below the recommendations (about $2.5 \mathrm{~g} / 15 \mathrm{~g}$ ) of the International Society of Sports Nutrition (ISSN).

Collagen peptides are more resistant to peptidases due to their small molecule size and the high proportion of proline and hydroxyproline. As a result, collagen peptides are rapidly absorbed from the gastrointestinal tract also in peptide form [11-14]. Moreover, it has been shown that specific collagen peptides could act as signal messengers in anabolic cellular processes in cartilage, tendons and ligaments [15-17], which might be the reason for improved pain symptoms and performance in activity-related joint discomforts [18-20], tendinopathy [21,22] and chronic ankle instability [23] in physically active adults.

The stimulation of the muscular anabolic pathways may, therefore, also be enhanced by peptides containing non-essential amino acids rather than only by leucine or other BCAA [24-26]. The results of a previous study showed that the intake of $15 \mathrm{~g}$ of specific collagen peptides significantly increased fat free mass following RT in older men with sarcopenia [10]. There is evidence of age-related differences in the effects of RT on muscle mass and in the utilization of dietary proteins $[27,28]$.

The aim of the present study was, therefore, to examine the effect of supplementation with $15 \mathrm{~g}$ of specific collagen peptides in combination with RT on body composition and muscle strength in order to evaluate if the positive results from a sarcopenic population could be confirmed in a younger male population (30-60 years).

Regarding the results of the previous study with specific collagen peptides [10], the main hypothesis of the main analysis was that also in these younger study participants, the supplementation of specific collagen peptides in combination with RT would improve body composition (increase in muscle mass and decrease in fat mass) and muscle strength compared to placebo.

It is generally accepted that whey protein supplementation in combination with RT programs has a beneficial effect on anabolic processes in the skeletal muscle [7]. In contrast, the scientific knowledge about the effect of collagen peptides in muscle metabolism is less investigated, so far. Therefore, in the exploratory part of the study, the results obtained after taking collagen peptide were compared with the data of a study group that received a daily dosage of $15 \mathrm{~g}$ whey protein in combination with RT.

\section{Materials and Methods}

\subsection{Study Design and Participants}

The study was designed as a monocentric, prospective, placebo-controlled, doubleblinded trial conducted at the University of Freiburg, Germany. In total, 120 overweight men (body mass index $=27.5$ to 35 , fat mass $>25 \%$ ) were recruited. To examine a homogenous age group considering the muscle metabolism, the participants were aged between 30 and 60 years [29]. Based on the data of a previous trial in older men with reduced muscle mass and function [10], the sample size was determined by a power calculation using G*Power (University of Düsseldorf, Düssseldorf, Germany). To ensure a sedentary 
life-style of the study population, participation in the study was not possible if participants had performed regular physical activity for more than $60 \mathrm{~min}$ a week during the past year. Unstable weight and eating behavior were also defined as exclusion criteria, since changes in lifestyle may have an impact on the respective outcome. In this study, participants had to follow a 12-week resistance training in combination with the supplementation of collagen peptides, whey protein or silicon dioxide. Contraindications to physical activity in accordance with American College of Sports Medicine (ACSM) guidelines such as cardiovascular, metabolic or renal diseases [30], or contraindications to the intake of the investigational products diagnosed from anamnestic data also led to an exclusion of the screened participants.

Following written informed consent, participants were assigned to the study groups using a web-based random number generator [31]. Although the whey group was not part of the main analysis, this group was included in the randomization with the same number of participants as in the CP-G and P-G to be sure of minimizing the likelihood of differential treatment or outcome assessments by blinding both participants and researchers. Participants were instructed not to change their diet and physical activities apart from the intake of the product under investigation and the one-hour training session three times a week. In addition, they were asked to complete a three-day nutrition protocol, which included two weekdays and one day at the weekend, both before and after the intervention. All subjects were instructed by a nutritionist on how to quantify the ingested foods using household measurements. The test products were not included in the food record. The protocols were analyzed for daily energy and macronutrient intake using EBISPro 7.0 (EBISPro Stuttgart/Hohenheim, Germany).

The participants were asked to record the time of ingestion and any side effects of the supplement or problems relating to the training program. Blood samples to test routine clinical parameters, including creatine kinase and urea, were taken before and after the intervention. Blood sample collection was performed by a licensed physician.

For $\mathrm{t} 0$ (pre-test) and $\mathrm{t} 12$ (post-test), the participants were asked to arrive at the University of Freiburg at the same time in the morning and were told to consume the same foods and liquids the day prior to both examinations. Screening began with a medical history questionnaire to ensure the inclusion criteria were met and that there were no risk factors involved that might be aggravated by the exercise protocol.

The examination was approved by the Ethics Committee of the University of Freiburg and registered at the German Clinical Trials Register (DRKS00008925).

\subsection{Efficacy Outcomes}

The primary endpoint of this study was to compare differences in fat free mass between the group receiving collagen peptides (CP-G) and the placebo group (P-G). The respective differences in fat free mass were calculated by subtracting the fat free mass (measured in $\mathrm{kg}$ ) at the end of the study (t12) from the initial value ( $\mathrm{t} 0)$. Comparing the changes in fat mass, body weight and waist circumference between $\mathrm{CP}-\mathrm{G}$ and $\mathrm{P}-\mathrm{G}$ were defined as the secondary endpoints.

The body composition evaluation was performed at baseline and again after three months of intervention by DXA measurement (Stratos DR Dual Fan Beam, Degen Medizintechnik, Heppenheim, Germany). DXA and isometric strength testing were conducted by the same trained and qualified investigator. The DXA scan was calibrated in accordance with the manufacturer's instructions before each measurement by a phantom scan. While wearing the skintight clothing and no detachable metallic objects, lying straight on the table, participants were subjected to a full body DXA scan to assess various body composition characteristics (fat free mass, explicitly lean mass and fat mass). In addition, the participants had to void bladder before the measurement. Alcoholic beverages and intense exercises had to be avoided $48 \mathrm{~h}$ prior to examination.

Comparing the changes in the maximum voluntary isometric contraction $(\mathrm{N})$ between $\mathrm{CP}-\mathrm{G}$ and P-G was also considered as secondary endpoint. The isometric strength testing 
was determined as the mean value of pressing three times bilaterally using a 90-degree leg press device with an integrated foot force platform (Kistler ${ }^{\circledR}$, Winterthur, Schweiz). In the exploratory part of the study, the effect of whey protein supplementation (WP-G) on changes in fat free mass, fat mass, bodyweight, waist circumference and muscle strength were determined and compared with $\mathrm{CP}-\mathrm{G}$ and $\mathrm{P}-\mathrm{G}$.

\subsection{Investigational Products}

A specific mixture of bioactive collagen peptides (BODYBALANCE ${ }^{\circledR}$, Gelita AG, Germany) were used for this study. The placebo consisted of silicon dioxide, and the whey protein was a whey isolate (Volactive ${ }^{\circledR} 90 \%$, Hertfordshire, UK). Table S1 shows the amino acid composition of the collagen peptides and the whey protein.

All of the test products were packed in single sachets containing a daily dose of $15 \mathrm{~g}$. The powders had to be dissolved in $250 \mathrm{~mL}$ of water at room temperature and ingested once daily. Participants were instructed to drink the solution within an hour after training. On days without training, the test products had to be ingested at the same time as on training days.

To check compliance, supplements not used were collected from the subjects at the final visit. In addition, the supplementation was documented in the compliance calendar.

\subsection{Exercise Intervention Program}

Sixty minutes of supervised RT was conducted at the University of Freiburg at the same time of day ( 8 a.m. -8 p.m.). The protocol was based on recommendations for RT in a healthy untrained population to improve muscular strength and hypertrophy [6]. The sessions were performed three times weekly over a period of 12 weeks. Training began with a ten minute cardio-training ( 50 to $100 \mathrm{~W}$ ) to warm up. The three-set program included horizontal leg presses (both legs), reverse crunches, lat-pull exercise, sit-ups and chest presses with 1 to 2 min rest periods between sets. The load was adjusted individually to facilitate the proper execution of the required repetitions as follows: week 1-2: fifteen repetitions with $70 \%$ of one repetition maximum (RM), week 3-4: twelve repetitions with $75 \%$ of $1 \mathrm{RM}$, week $5-8$ : ten repetitions with $80 \%$ of 1 RM; week 9-12: eight repetitions with $85 \%$ of $1 \mathrm{RM}$. If all sets were performed with the correct technique, the load was increased by 5 to $10 \%$. Researchers noted the participants' load for each exercise in every RT session.

The data were evaluated on the basis of all participants that completed the trial and complied with the study protocol (per protocol population). A protocol violation was defined as any notable deviation from the study protocol procedures. An effect of the study supplements could be expected if at least $80 \%$ of the supplements were taken [32]. Compliance was therefore monitored by the collection of unused samples, and participants were excluded from the analysis if less than $80 \%$ of the supplements were taken. Compliance for resistance training was defined as documentation of at least 30 training sessions of the scheduled 36 sessions. This compliance level was chosen in accordance with the current ACSM recommendations on resistance training [6].

\subsection{Statistical Analysis}

All data are presented as mean \pm standard deviation (SD) in tables and text and mean \pm the $95 \%$ confidence interval (95\% CI) in figures. SPSS statistics (IBM SPSS Statistics for Windows, Version 23.0. Armonk, NY, USA: IBM Corp.) was used for all statistical analyses. All of the tests in the descriptive analysis were performed as two-sided tests, and the significance level was set at $\alpha=0.05$.

Data distribution was examined with a Shapiro-Wilk test. In case of normal distribution, the homogeneity of the baseline values between the study groups was checked by using one-way ANOVA. Otherwise, the Kruskal-Wallis test was used.

For the main analysis, the mean differences in the primary and secondary endpoints obtained from CP-G and P-G were compared using a linear mixed model (LMM) for continuous variables. The factors were treatment (BODYBALANCE ${ }^{\circledR}$ and placebo) and 
time (pre- and post-intervention levels). For the exploratory part of the study, mean differences of the same parameters obtained from all of the groups were also compared using LMM for continuous variables. The factors were treatment (BODYBALANCE ${ }^{\circledR}$, placebo and whey protein) and time (pre- and post-intervention levels). Post hoc tests were performed for CP-G vs. WP-G and for P-G vs. WP-G. The comparison of CP-G vs. P-G was already performed in the main analysis. The changes in body composition and muscle strength during the intervention period within the groups were analyzed using the paired sample t-test, or the Wilcoxon signed-rank test when the data could not be assumed to be distributed normally. As a magnitude of the difference between groups, the effect sizes were calculated from differences in means between groups at the end of the investigation (Cohen's d with correction according to Hedges).

\section{Results}

\subsection{Subjects}

A total of 120 adult males met the inclusion criteria and were randomized (Figure 1). The per-protocol population (PP-Population) included 61 participants in the main analysis. The exploratory analysis included 97 participants. Thirty participants in the CP-G, 31 participants in the P-G and 36 participants in the WP-G were analyzed. Reasons for premature study termination or exclusion from the analysis are shown in Figure 1. The exclusion of participants was related to missing the training protocol for $>6$ times (non-compliance with the study protocol). None of the dropouts were related to side-effects or adverse events caused by the intake of collagen peptides, placebo or whey protein. No adverse events were noted for the PP-population, and no pathological findings were observed in the routine blood tests, including creatine kinase and urea.

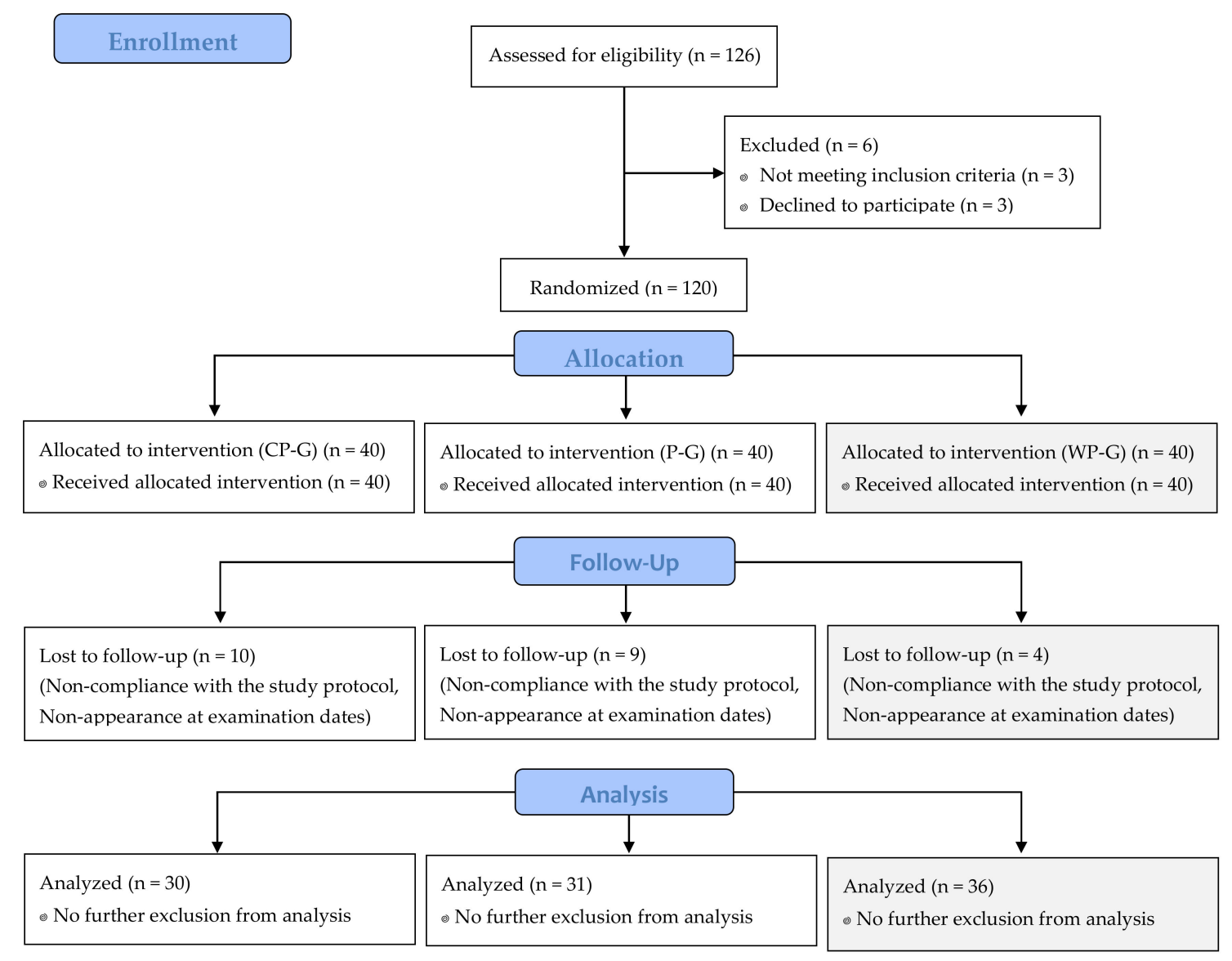

Figure 1. Flow chart of subject recruitment, randomization and follow-up. 
The baseline data of the study participants are summarized in Table 1. No statistically significant differences for any demographic result were observed between the study groups of the main and exploratory analysis at the beginning of the study (Table 1).

Table 1. Baseline data (T0) for the analyzed population $(n=97)$.

\begin{tabular}{ccccc}
\hline & CP-G $(\mathbf{n}=\mathbf{3 0})$ & P-G $(\mathbf{n}=\mathbf{3 1})$ & WP-G $(\mathbf{n}=\mathbf{3 6})$ & $p$ Value \\
\hline Age $(\mathrm{y})$ & $51.8 \pm 4.56$ & $47.4 \pm 7.26$ & $49.6 \pm 7.98$ & $0.058^{\#}$ \\
Height $(\mathrm{m})$ & $1.80 \pm 0.07$ & $1.79 \pm 0.05$ & $1.80 \pm 0.06$ & $0.596^{*}$ \\
Body weight $(\mathrm{kg})$ & $99.6 \pm 9.00$ & $95.5 \pm 10.8$ & $98.3 \pm 11.5$ & $0.293^{\#}$ \\
BMI $\left(\mathrm{kg} / \mathrm{m}^{2}\right)$ & $31.0 \pm 2.93$ & $29.9 \pm 2.56$ & $30.2 \pm 2.60$ & $0.416^{\#}$ \\
BP sys $(\mathrm{mm} \mathrm{Hg})$ & $143.3 \pm 16.9$ & $136.3 \pm 16.0$ & $141.6 \pm 16.3$ & $0.241^{\#}$ \\
BP dia $(\mathrm{mm} \mathrm{Hg})$ & $91.5 \pm 8.63$ & $87.4 \pm 10.3$ & $89.4 \pm 9.32$ & $0.180^{\#}$ \\
\hline Data represent mean \pm SD; differences between all groups tested with * analysis of variance, ${ }^{\text {\# }}$ Kruskal-Wallis Test.
\end{tabular}

\subsection{Main Analysis of Body Composition and Muscle Strength}

The baseline data of the respective outcomes of the main analysis are summarized in Table 2. No significant baseline differences between the study groups were detected except for waist circumference. For this parameter, the baseline data were imbalanced with a significantly lower mean waist circumference in the P-G in comparison with the CP-G $(p=0.011)$.

Table 2. Efficacy outcomes at baseline and following supplementation with collagen peptides or placebo.

\begin{tabular}{cccccc}
\hline & \multicolumn{2}{c}{ CP-G (n = 30) } & \multicolumn{2}{c}{ P-G (n = 31) } & T12 \\
\cline { 2 - 5 } & T0 & T12 & T0 & Value LMM \\
\hline Fat free mass (kg) & $60.4 \pm 4.78$ & $63.8 \pm 6.03^{* * *}$ & $58.5 \pm 6.29$ & $60.3 \pm 5.71^{* * *}$ & $\mathbf{0 . 0 1 0}$ \\
Fat free mass (\%) & $60.8 \pm 4.50$ & $65.3 \pm 4.76^{* * *}$ & $61.4 \pm 4.31$ & $64.4 \pm 5.02^{* * *}$ & 0.023 \\
Skeletal muscle mass & $30.8 \pm 2.42$ & $32.1 \pm 3.02^{* * *}$ & $30.0 \pm 3.18$ & $30.5 \pm 2.85^{*}$ & 0.011 \\
Fat mass (kg) & $35.9 \pm 7.11$ & $30.6 \pm 6.48^{* * *}$ & $33.7 \pm 6.89$ & $30.3 \pm 7.57^{* * *}$ & 0.023 \\
Fat mass (\%) & $35.8 \pm 4.71$ & $31.1 \pm 5.06^{* * *}$ & $35.1 \pm 4.53$ & $31.9 \pm 5.30^{* * *}$ & 0.031 \\
Bone mineral content (kg) & $3.34 \pm 0.339$ & $3.57 \pm 0.460^{* *}$ & $3.34 \pm 0.380$ & $3.49 \pm 0.442^{*}$ & 0.330 \\
Bone mineral content (\%) & $3.37 \pm 0.376$ & $3.66 \pm 0.439^{* * *}$ & $3.52 \pm 0.371$ & $3.76 \pm 0.533^{* *}$ & 0.602 \\
Body weight (kg) & $99.6 \pm 9.00$ & $98.0 \pm 8.49^{* * *}$ & $95.5 \pm 10.8$ & $94.1 \pm 10.8^{*}$ & 0.743 \\
Waist circumference (cm) & $107.5 \pm 6.67^{\dagger}$ & $104.1 \pm 6.49^{* * *}$ & $102.9 \pm 7.00^{+}$ & $100.4 \pm 7.77^{* *}$ & 0.292 \\
Muscle strength (N) & $1695 \pm 378.7$ & $1858 \pm 399.2^{* * *}$ & $1706 \pm 351.8$ & $1806 \pm 365.9^{* *}$ & 0.158 \\
\hline
\end{tabular}

Data represent mean $\pm \mathrm{SD} ; p$ value LMM, significance between groups in linear mixed model testing assessing treatment $\times$ time interaction;

${ }^{+}=p<0.05$ between groups at baseline; ${ }^{*}=p<0.05 ;{ }^{* *}=p<0.01 ;{ }^{* * *}=p<0.001$ within the group from baseline to final examination.

${ }^{1}$ Estimated skeletal muscle mass according to Kim et al. [33]. Bold numbers represent statistical significance of the primary endpoint.

The current investigation identified a significant improvement in fat free mass, fat mass, muscle strength and waist circumference in all groups (Table 2). Moreover, bone mineral content and skeletal muscle mass increased statistically significantly $(p<0.05)$ in all groups during the course of the study.

The main analysis showed that the specific collagen peptide supplementation exhibited a statistically significantly $(p=0.010)$ greater gain in fat free mass $(\Delta C P-G=3.42 \pm 2.54 \mathrm{~kg})$ than placebo $(\Delta \mathrm{P}-\mathrm{G}=1.83 \pm 2.09 \mathrm{~kg})$, as seen in Figure 2 . The additional increase in fat free mass by collagen peptide supplementation was also reflected by the medium to large effect size of $d=0.676$ compared with placebo. These results are in line with the changes in the estimated skeletal muscle mass $(\Delta \mathrm{CP}-\mathrm{G}=1.23 \pm 1.25 \mathrm{~kg} ; \Delta \mathrm{P}-\mathrm{G}=0.514 \pm 1.05 \mathrm{~kg} ; p=0.011$; $\mathrm{d}=0.621)$. The decrease in fat mass was also statistically significantly higher $(p=0.023)$ in CP-G $(\triangle \mathrm{CP}-\mathrm{G}=-5.28 \pm 3.19 \mathrm{~kg})$ compared with $\mathrm{P}-\mathrm{G}(\Delta \mathrm{P}-\mathrm{G}=-3.39 \pm 3.13 \mathrm{~kg})$. The clinical relevance of these results was confirmed by the effect size $(\mathrm{d}=0.579)$. Muscle strength increased by $163 \mathrm{~N}(\sim 16.3 \mathrm{~kg})$ in CP-G and $100 \mathrm{~N}(\sim 10 \mathrm{~kg})$ in P-G. The higher increase in muscle strength by the additional intake of collagen peptides after the training sessions compared with placebo did not reach the level of significance and had an effect 
size of $d=0.366$. The decrease in waist circumference was more pronounced in the CP-G $(-3.41 \pm 2.22 \mathrm{~cm})$ compared with the P-G $(-2.50 \pm 4.19 \mathrm{~cm})$, but the group differences were not statistically significant $(p=0.292 ; \mathrm{d}=0.270)$.

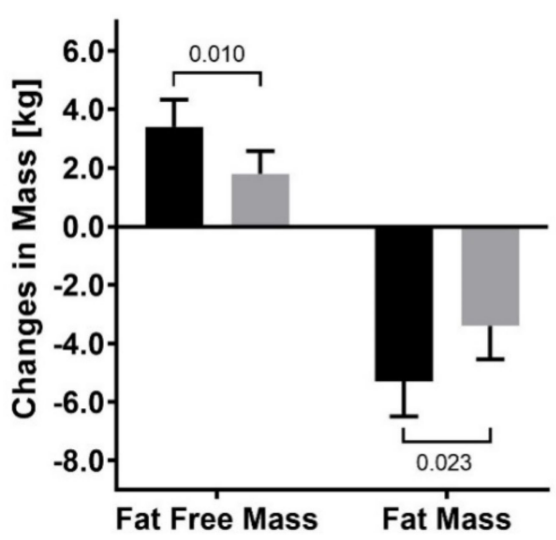

(A)

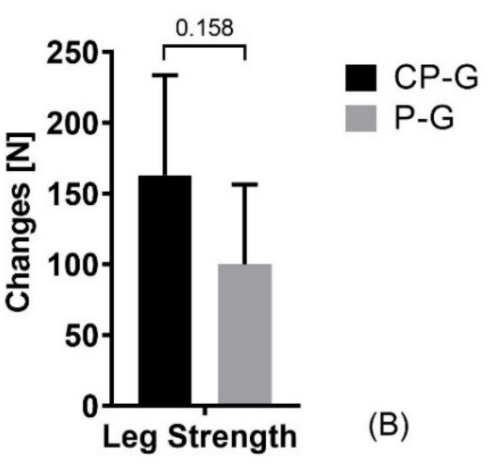

Figure 2. Absolute changes in (A) body composition and (B) isometric muscle strength at the end of the study compared between groups of the main analysis (CP-G vs. P-G). Data are shown as mean $\pm 95 \%$ CI; $p$ values $<0.05$ were considered significant.

An intention to treat analysis was also performed. The results of this approach confirmed the findings of the PP-analysis.

\subsection{Exploratory Analysis of Body Composition and Muscle Strength}

As shown in Table 3, the results of the exploratory analysis revealed statistically significant differences between all study groups with respect to fat free mass $(p=0.033)$. No statistically significant differences were observed when comparing the gain in fat free mass in WP-G $(\Delta \mathrm{WP}-\mathrm{G}=2.27 \pm 2.56 \mathrm{~kg})$ with the results of the CP-G $(p=0.074)$ or P-G $(p=0.442)$ in the post hoc analysis. In contrast to the collagen peptide supplementation, the whey protein treatment showed a small effect $(\mathrm{d}=0.185)$. Similarly, the changes in estimated skeletal muscle mass in WP-G $(\triangle \mathrm{WP}-\mathrm{G}=0.728 \pm 1.27 \mathrm{~kg})$ were not statistically significantly different from the changes in CP-G $(p=0.076)$ or P-G $(p=0.460)$ in the post hoc analysis. Furthermore, the whey protein supplementation had a smaller effect on changes in the skeletal muscle mass $(\mathrm{d}=0.184)$ compared to collagen peptides. Concerning fat mass, no statistically significant difference between all of the groups was observed $(p=0.054)$. The decrease in fat mass in WP-G $(\Delta \mathrm{WP}-\mathrm{G}=-4.08 \pm 2.80 \mathrm{~kg})$ did not achieve statistical significance equivalent to the differences between CP-G $(p=0.111)$ and P-G $(p=0.341)$ in the post hoc analysis. Again, the intake of whey protein seemed to be less effective than collagen peptides when compared to placebo $(\mathrm{d}=0.228)$.

Participants following RT in combination with whey protein supplementation improved their muscle strength by $120 \mathrm{~N}(\sim 12 \mathrm{~kg})$. Comparing the changes in muscle strength between WP-G and CP-G $(p=0.417)$ or P-G $(p=0.685)$, a low effect $(\mathrm{d}=0.100)$ and no statistical differences were detected. The decrease in waist circumference in the WP-G $(-2.51 \pm 4.56 \mathrm{~cm})$ was not statistically significantly different when compared with CP-G $(p=0.323)$ or P-G $(p=0.996)$. Taking the P-G as reference, the additional effect of whey protein supplementation was very small $(\mathrm{d}=0.002)$. 
Table 3. Efficacy outcomes at baseline and following supplementation with collagen peptides, whey protein or placebo.

\begin{tabular}{|c|c|c|c|c|c|c|c|}
\hline & \multicolumn{2}{|c|}{ CP-G $(n=30)$} & \multicolumn{2}{|c|}{ P-G (n = 31) } & \multicolumn{2}{|c|}{ WP-G (n = 36) } & \multirow{2}{*}{$p$ Value LMM } \\
\hline & T0 & T12 & T0 & T12 & T0 & T12 & \\
\hline Fat free mass (kg) & $60.4 \pm 4.78$ & $63.8 \pm 6.03^{* * *}$ & $58.5 \pm 6.29$ & $60.3 \pm 5.71^{* * *}$ & $59.6 \pm 6.22$ & $61.9 \pm 6.76^{* * *}$ & 0.033 \\
\hline Fat free mass $(\%)$ & $60.8 \pm 4.50$ & $65.3 \pm 4.76^{* * *}$ & $61.4 \pm 4.31$ & $64.4 \pm 5.02 * * *$ & $60.8 \pm 3.29$ & $64.3 \pm 4.67^{* * *}$ & 0.066 \\
\hline Skeletal muscle mass ${ }^{1}$ & $30.8 \pm 2.42$ & $32.1 \pm 3.02^{* * *}$ & $30.0 \pm 3.18$ & $30.5 \pm 2.85 *$ & $30.5 \pm 3.13$ & $31.2 \pm 3.33^{* *}$ & 0.037 \\
\hline Fat mass (kg) & $35.9 \pm 7.11$ & $30.6 \pm 6.48^{* * *}$ & $33.7 \pm 6.89$ & $30.3 \pm 7.57^{* * *}$ & $35.4 \pm 6.44$ & $31.3 \pm 7.40^{* * *}$ & 0.054 \\
\hline Fat mass $(\%)$ & $35.8 \pm 4.71$ & $31.1 \pm 5.06^{* * *}$ & $35.1 \pm 4.53$ & $31.9 \pm 5.30^{* * *}$ & $35.8 \pm 3.45$ & $32.1 \pm 4.94^{* * *}$ & 0.083 \\
\hline Bone mineral content $(\mathrm{kg})$ & $3.34 \pm 0.339$ & $3.57 \pm 0.460 * *$ & $3.34 \pm 0.380$ & $3.49 \pm 0.442 *$ & $3.25 \pm 0.350$ & $3.40 \pm 0.311^{* *}$ & 0.325 \\
\hline Bone mineral content $(\%)$ & $3.37 \pm 0.376$ & $3.66 \pm 0.439^{* * *}$ & $3.52 \pm 0.371$ & $3.76 \pm 0.533^{* *}$ & $3.37 \pm 0.393$ & $3.58 \pm 0.423^{* * *}$ & 0.642 \\
\hline Body weight $(\mathrm{kg})$ & $99.6 \pm 9.00$ & $98.0 \pm 8.49^{* * *}$ & $95.5 \pm 10.8$ & $94.1 \pm 10.8^{*}$ & $98.3 \pm 11.5$ & $96.6 \pm 11.5^{* * *}$ & 0.899 \\
\hline Waist circumference $(\mathrm{cm})$ & $107.5 \pm 6.67^{\dagger}$ & $104.1 \pm 6.49^{* * *}$ & $102.9 \pm 7.00^{\dagger}$ & $100.4 \pm 7.77^{* *}$ & $105.6 \pm 7.11$ & $103.2 \pm 7.86^{* * *}$ & 0.561 \\
\hline Muscle strength (N) & $1695 \pm 378.7$ & $1858 \pm 399.2^{* * *}$ & $1706 \pm 351.8$ & $1806 \pm 365.9^{* *}$ & $1633 \pm 370.5$ & $1753 \pm 355.7^{* *}$ & 0.444 \\
\hline
\end{tabular}

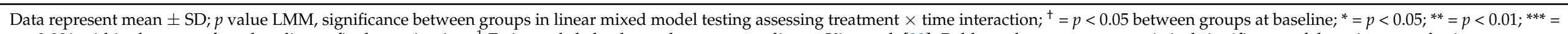
$p<0.001$ within the group from baseline to final examination. ${ }^{1}$ Estimated skeletal muscle mass according to Kim et al. [33]. Bold numbers represent statistical significance of the primary endpoint. 


\subsection{Dietary Intake}

There were no significant differences between the participants' mean energy and macronutrient intakes prior to the first testing session. According to the analysis of dietary behavior (Table 4), the absolute and relative protein intake did not change during the observation period in any of the groups, and none of the participants were protein deficient. During the course of the study, a statistically significant $(p=0.043)$ reduction in energy intake and a tendential decrease in carbohydrate intake $(p=0.079)$ could be observed in the P-G. As a potential consequence, the energy $(p=0.016)$ and carbohydrate intake $(p=0.026)$ in post-intervention assessment differed significantly between CP-G and P-G.

Table 4. Dietary patterns at baseline and following supplementation with collagen peptides, whey protein or placebo.

\begin{tabular}{|c|c|c|c|c|c|c|c|}
\hline & \multicolumn{2}{|c|}{ CP-G $(n=30)$} & \multicolumn{2}{|c|}{ P-G (n = 31) } & \multicolumn{2}{|c|}{ WP-G (n = 31) } & \multirow{2}{*}{$\begin{array}{c}p \text { Value } \\
\text { LMM }\end{array}$} \\
\hline & T0 & T12 & T0 & T12 & T0 & T12 & \\
\hline Energy (kcal) & $2739 \pm 672.8$ & $2863 \pm 686.4$ & $2573 \pm 585.7$ & $2419 \pm 614.9^{*}$ & $2780 \pm 897.6$ & $2619 \pm 791.5$ & 0.059 \\
\hline Protein $(\mathrm{g})$ & $105.0 \pm 20.7$ & $107.0 \pm 28.1$ & $102.8 \pm 29.1$ & $96.6 \pm 28.1$ & $108.1 \pm 34.0$ & $103.2 \pm 34.2$ & 0.508 \\
\hline Protein (g/kg BW) & $1.05 \pm 0.209$ & $1.10 \pm 0.289$ & $1.09 \pm 0.318$ & $1.03 \pm 0.304$ & $1.11 \pm 0.385$ & $1.08 \pm 0.360$ & 0.750 \\
\hline Protein $(\%)$ & $16.1 \pm 2.78$ & $15.6 \pm 3.08$ & $16.4 \pm 3.45$ & $16.5 \pm 3.11$ & $16.2 \pm 3.42$ & $16.2 \pm 2.65$ & 0.469 \\
\hline Fat $(\mathrm{g})$ & $113.3 \pm 37.4$ & $116.9 \pm 36.4$ & $100.4 \pm 24.4$ & $99.6 \pm 31.6$ & $116.6 \pm 48.2$ & $118.5 \pm 48.1$ & 0.855 \\
\hline Fat $(\%)$ & $37.0 \pm 7.37$ & $36.1 \pm 5.23$ & $34.2 \pm 6.96$ & $36.6 \pm 5.12$ & $36.5 \pm 5.17$ & $38.6 \pm 6.67$ & 0.155 \\
\hline Carbohydrates (g) & $282.8 \pm 95.6$ & $301.4 \pm 85.8$ & $276.8 \pm 79.6$ & $253.7 \pm 76.6$ & $268.2 \pm 92.2$ & $253.0 \pm 75.5$ & 0.060 \\
\hline Carbohydrates (\%) & $42.5 \pm 7.91$ & $43.0 \pm 6.97$ & $43.8 \pm 6.92$ & $43.0 \pm 7.11$ & $41.4 \pm 7.15$ & $40.1 \pm 7.06$ & 0.669 \\
\hline
\end{tabular}

Data represent mean $\pm \mathrm{SD} ; p$ value LMM, significance between groups of in linear mixed model testing assessing treatment $\times$ time interaction. ${ }^{*}=p<0.05$ within the group from baseline to final examination.

\section{Discussion}

The current investigation observed a significant increase in fat free mass following the 12-week RT program. The increase in fat free mass was significantly higher in the group receiving a daily dosage of $15 \mathrm{~g}$ specific collagen peptides compared to placebo. In the exploratory part, whey protein ingestion further improved fat free mass, but this effect was not statistically different from placebo. In addition, there were no significant differences between collagen peptides and whey protein with respect to changes in fat free mass.

To our best knowledge there are no previous studies that have focused on the effects of collagen peptides in a middle-aged, untrained male population.

Current evidence suggests that an average gain in fat free mass of $1.1 \mathrm{~kg}$ can be obtained by a training intervention lasting at least 10 weeks [5]. Current data from controlled trials and meta-analyses suggest that protein ingestion potentiates the effects of RT. In meta-analysis, the mean differences of fat free mass between protein supplementation and placebo is reported as $0.3-1.0 \mathrm{~kg}[7,34,35]$. According to a previous review, gains in lean mass as a result of resistance training combined with protein supplementation in trained and untrained adults ranged from 0.2 to $5 \mathrm{~kg}$ [36]. These data are congruent with the findings of the present trial. Taking the placebo as a reference, the effect of whey protein in this trial was an additional increase in fat free mass of $0.5 \mathrm{~kg}$ while the administration of the applied specific collagen peptide resulted in a $1.6 \mathrm{~kg}$ greater gain in fat free mass.

In a previous investigation, a 12-week RT combined with the supplementation of $15 \mathrm{~g}$ of specific collagen peptides showed a positive effect on body composition, which resulted in a $1.3 \mathrm{~kg}$ higher gain in fat free mass compared to placebo in elderly sarcopenic men [10]. Newly published data from an investigation with a comparable study designed have shown that the daily intake of $15 \mathrm{~g}$ specific collagen peptides combined with a 12-week RT program led to a significantly higher increase in fat free mass and improvement in strength tests compared to the RT program alone [37]. In contrast to the present investigation, the respective study population was young and RT-experienced men. In another study with participants experienced in RT, the effects of collagen peptide intake on reducing muscle fatigue and improving performance were comparable to whey protein [38]. How- 
ever, the trial did not include a control group without protein supplementation after the training sessions.

Previous studies have shown that changes in muscle mass induced by RT were associated with the mTOR signaling pathway. It has been demonstrated that protein synthesis is controlled by mTOR at numerous levels and that protein supplementation (especially BCAA) will further improve anabolic stimuli in skeletal muscles via the mTOR pathway [8]. However, the positive effects of collagen peptides cannot solely be explained by the amount and composition of amino acids. The amount of leucine and BCAA in collagen does not seem to be sufficient to stimulate the mTOR pathway in a comparable manner than whey protein. On the other hand, previous publications have demonstrated that mTOR is also activated by other amino acids, e.g., glycine [24,26]. Collagen peptides have a high glycine content. Therefore, this amino acid might also be responsible for the stimulatory effect of collagen peptides on mTOR. According to recent results by Kitakaze et al., Hyp-Gly-dipeptides that occur frequently in collagen peptides also stimulate myogenic differentiation via the mTOR signaling pathway. In a recent study with RT experienced male participants, the effect of specific collagen peptides on fat free mass was examined on the gene level using a muscle biopsy. The results of the proteome analysis revealed a higher number of upregulated proteins in the group receiving specific collagen peptides compared to the placebo group. The upregulated proteins in the collagen peptide group were predominantly associated with the metabolism of the contractile elements [39]. Thus, amino acids present in high amounts in collagen peptides could also act as signaling molecules in skeletal muscle anabolism [25]. However, more research is needed to determine the anabolic effects of collagen peptides in the mTOR pathway.

One possible explanation for the lower effects of whey protein on fat free mass is that the amount of whey protein $(15 \mathrm{~g} / \mathrm{d})$ was insufficient to induce optimal effects. The latest recommendation of the ISSN for high-quality proteins after RT are $20 \mathrm{~g}(0.25 \mathrm{~g} / \mathrm{kg}$ body weight) in young and middle-aged adults [9]. By contrast, the sufficient dose of collagen peptides to increase the fat free mass [40] seems to be 10-15 g. The disparity of the results might be related to the different composition and the mode of action of the protein supplements used. It has been widely accepted that whey protein has a stimulatory effect in the muscle metabolism due to their high content in BCAA [8]. In contrast, the effects of collagen peptides cannot be explained by its BCAA content. First experiments suggest that the interaction between the specific collagen peptides and integrin receptors (e.g., subtype $\alpha 11 \beta 1)$ might be the key factor for stimulation of muscle protein synthesis [41,42].

Other explanations for the higher increase in fat free mass after collagen peptide supplementation include the theory that about $10 \%$ of skeletal muscles consist of collagen, which makes a major contribution to the function and biochemical structure of skeletal muscles [43]. In addition, there is a close functional and anatomical connection between muscle and connective tissue [44,45]. Furthermore, the intramuscular ECM regulates the formation, maintenance and differentiation of myosatellite cells facilitating myofiber growth [46,47]. In vitro experiments showed a significant increase in collagen type I and III with collagen peptide treatment, which consequently led to improved tissue stability [15]. This effect was confirmed in a clinical trial that demonstrated an increase in the resilience and strength of connective tissue after collagen peptide intake [48]. Taking the data of the skeletal muscle mass into account, it could be speculated that part of the observed increase in fat free mass might also be related to the enhanced collagen content of the intramuscular connective tissue. However, this assumption needs to be verified by future muscle biopsy and magnetic resonance imaging studies, as the skeletal muscle mass was estimated by a formula according to Kim et al. [33] and not measured directly.

The significant changes in muscle strength can be explained by the RT, which is effective at substantially increasing muscular strength, when performed three times/week [49]. The WP-G and P-G participants achieved almost the same increase in isometric leg strength, whereas in $\mathrm{CP}-\mathrm{G}$ the gain in muscle strength was more than 1.5 times as high as in P-G (Table 3). A meta-analysis by Peterson et al. reported an average increase in strength 
of $20-30 \%$ irrespective of the measuring method used [5]. These findings correspond to current ACSM data [6]. It must be mentioned, however, that the increase in muscle strength is subject to a large variance $[5,6]$.

The current study furthermore revealed a statistically significant decrease in fat mass in all participants. The LMM provided no statistical levels for changes in fat mass in the overall comparison. However, the LMM analysis revealed that participants who had received collagen peptides decreased their fat mass statistically significantly by $5.3 \mathrm{~kg}$ compared with the placebo group with a fat mass reduction of $3.4 \mathrm{~kg}$. This finding is consistent with the results of a previous study on sarcopenic men who received the same dose of the identical collagen peptide composition [10]. In this trial, collagen peptide supplementation led to a statistically significant fat mass reduction of $5.5 \mathrm{~kg}$ and a decrease of fat mass by $2.9 \mathrm{~kg}$ in the placebo group. The exploratory analysis revealed no statistical differences between WP-G and CP-G or P-G. The divergence of fat mass in this trial might be partly explained by a higher resting energy expenditure caused by the more pronounced gain in fat free mass in the CP-G. This explanatory approach is speculative. Future investigations concerning body composition need to include measurement of the resting metabolism. In the present study, a moderate reduction of $2.3 \%$ in the waist circumference could be observed in the WP-G and P-G. In the group of participants that had received the specific collagen peptides the effect was slightly higher with a decrease of $3.1 \%$. It is assumed that considerably enhanced body fat mass - especially visceral fat-is positively correlated with an increased waist circumference and the main cause of the metabolic syndrome [50]. According to a large cohort study, RT is effective in reducing waist circumference due to favorable changes in body composition [51]. These findings are in accordance with newly published data that shows various RT regimes lead to a significant decrease in fat mass and consequently an improved metabolic profile, including the waist circumference in untrained people [49,52]. An additional effect on the waist circumference in the CP-G could result from the intake of the specific collagen peptides due to a greater gain in fat free mass and loss in fat mass.

The results of the bone mineral content suggest that the osteoprotective effect of the intervention is the consequence of the training program [53]. The effects of exercise without or in combination with protein supplementation on bone mass in non-osteoporotic middle-aged men are rather small. There is evidence that resistance training three times per week for four months resulted in a $2-4 \%$ gain in bone mineral density $(\sim 60-120 \mathrm{~g}$ bone mass) [54], which is in line with the current finding.

It is not assumed that the present results can be attributed to the caloric add-on of $60 \mathrm{kcal}(251 \mathrm{~kJ})$ of collagen peptides or whey protein. According to the findings of Hall et al., the additional daily energy intake needs to amount to about $215 \mathrm{kcal}(900 \mathrm{~kJ})$. A daily intake of a further $40 \mathrm{kcal}(170 \mathrm{~kJ})$ would result in a weight gain of $1.8 \mathrm{~kg}(4 \mathrm{lb})$ in five years [55]. Furthermore, none of the study groups significantly altered their protein intake or were deficient in protein.

It must be mentioned that the P-G showed a lower energy intake after 12 weeks. The significant differences of energy intake between the CP-G and P-G were associated with differences in the intake of carbohydrates. It seems plausible that there was an underreporting, since the reported energy intake of 2400 to $2800 \mathrm{kcal}$ is equivalent to the energy requirements of normal weight men of the respective age group [56,57]. However, the participants of the current investigation were overweight men. This assumption is supported by the changes in fat mass. Despite a lower energy intake, the fat loss in the P-G was smaller than in the CP-G or WP-G.

This trial has some limitations. With respect to the comparison in the exploratory analysis, there was an unequal sample size $\left(\mathrm{n}_{\mathrm{CP}-\mathrm{G}}=30 ; \mathrm{n}_{\mathrm{P}-\mathrm{G}}=31 ; \mathrm{n}_{\mathrm{WP}-\mathrm{G}}=36\right)$, but this had no influence on the statistical outcomes. Limitations of the nutritional protocol might entail an overreporting or rather underreporting of foods consumed [58]. As mentioned above, the amounts of whey protein may have been insufficient, but the study was designed so that the amount of whey protein did not differ from the dosage of collagen peptides. 
It must be mentioned that the demonstrated efficacy is referred to the specific collagen peptides used, since various collagen peptides differ in their composition and hence their bioavailability and mode of action.

Future research should focus on the role of collagen peptides in the direct regulation of anabolic or catabolic processes in skeletal muscles or fat tissue on a cellular level. Possible pathways include, e.g., the stimulation of collagen synthesis and the mTOR pathway.

Moreover, the effect of various collagen peptides that differ in their biochemical properties (e.g., the amino acid sequence) in combination with other training settings needs to be further elucidated.

\section{Conclusions}

This study examined in the main analysis whether the supplementation of specific bioactive collagen peptides in combination with RT three times a week for $60 \mathrm{~min}$ induced a statistically significantly higher increase in fat free mass and a greater reduction in fat mass than RT alone. The respective effects were also compared with a group receiving whey protein in an exploratory approach. It was found that, compared to placebo, the ingestion of specific collagen peptides (BODYBALANCE ${ }^{\circledR}$ ) resulted in a statistically significantly higher gain in fat free mass and loss in fat mass. It was also shown that this greater effect on muscle protein synthesis and reduction in fat mass was less pronounced after whey protein supplementation. However, there was no statistically significant difference in a direct comparison between the two protein supplements. Muscle strength increased significantly in all groups as a result of RT. The respective results refer to the specific collagen peptides used. How these effects are applicable to other collagen peptides needs to be clarified.

Supplementary Materials: The following are available online at https:/ / www.mdpi.com/article/10 .3390 /ijerph18094837/s1, Table S1: Amino Acid Profile (\% of Protein) of the collagen peptides and whey protein.

Author Contributions: Conceptualization, D.Z., P.J., S.O., A.G. and D.K.; methodology, D.Z., P.J., S.O., A.G. and D.K.; validation, D.Z., P.J. and D.K.; formal analysis, D.Z. and D.K.; investigation, D.Z., P.J. and D.K.; resources, D.K.; data curation, D.Z., P.J. and D.K.; writing—original draft preparation, D.Z.; writing-review and editing, P.J., S.O., A.G. and D.K.; visualization, D.Z.; supervision, D.K.; project administration, D.Z.; funding acquisition, D.K. All authors have read and agreed to the published version of the manuscript.

Funding: The specific collagen peptides (product name BODYBALANCE ${ }^{\circledR}$ ) were provided by GELITA GmbH, Eberbach, Germany. This research was in part funded by GELITA GmbH, Eberbach, Germany.

Institutional Review Board Statement: The study was conducted according to the guidelines of the Declaration of Helsinki, and approved by the independent Ethics Committee of the University of Freiburg (protocol code: 205-14 and date of approval: 2014/11/05).

Informed Consent Statement: Informed consent was obtained from all subjects involved in the study.

Data Availability Statement: Data sharing not applicable.

Acknowledgments: We would like to thank all the participants as well as the staff of the University of Freiburg who supported us with the examination.

Conflicts of Interest: The authors declare no conflict of interest. S.O. has given scientific lectures that were in parts supported by the GELITA AG. He is also coinventor of patents concerning the use of collagen peptides. All procedures performed in studies involving human participants were in accordance with the ethical standards of the institutional and/or national research committee, and with the 1964 Helsinki declaration and its later amendments or comparable ethical standards. The funders had no role in the design of the study; in the collection, analyses or interpretation of data; in the writing of the manuscript, or in the decision to publish the results. The authors responsible for data assessment and analysis have neither financial nor competing interests concerning the outcome of this investigation. After the study was finished, D.Z. started as researcher in the Collagen Research Institute, Kiel. 


\section{References}

1. Malafarina, V.; Uriz-Otano, F.; Iniesta, R.; Gil-Guerrero, L. Sarcopenia in the Elderly: Diagnosis, Physiopathology and Treatment. Maturitas 2012, 71, 109-114. [CrossRef] [PubMed]

2. Cruz-Jentoft, A.J.; Baeyens, J.P.; Bauer, J.M.; Boirie, Y.; Cederholm, T.; Landi, F.; Martin, F.C.; Michel, J.-P.; Rolland, Y.; Schneider, S.M.; et al. Sarcopenia: European Consensus on Definition and Diagnosis: Report of the European Working Group on Sarcopenia in Older People. Age Ageing 2010, 39, 412-423. [CrossRef]

3. Stephen, W.C.; Janssen, I. Sarcopenic-Obesity and Cardiovascular Disease Risk in the Elderly. J. Nutr. Health Aging 2009, 13, 460-466. [CrossRef] [PubMed]

4. Stenholm, S.; Harris, T.B.; Rantanen, T.; Visser, M.; Kritchevsky, S.B.; Ferrucci, L. Sarcopenic Obesity: Definition, Cause and Consequences. Curr. Opin. Clin. Nutr. Metab. Care 2008, 11, 693-700. [CrossRef]

5. Peterson, M.D.; Sen, A.; Gordon, P.M. Influence of Resistance Exercise on Lean Body Mass in Aging Adults: A Meta-Analysis. Med. Sci. Sports Exerc. 2011, 43, 249-258. [CrossRef] [PubMed]

6. American College of Sports Medicine American College of Sports Medicine Position Stand. Progression Models in Resistance Training for Healthy Adults. Med. Sci Sports Exerc. 2009, 41, 687-708. [CrossRef] [PubMed]

7. Morton, R.W.; Murphy, K.T.; McKellar, S.R.; Schoenfeld, B.J.; Henselmans, M.; Helms, E.; Aragon, A.A.; Devries, M.C.; Banfield, L.; Krieger, J.W.; et al. A Systematic Review, Meta-Analysis and Meta-Regression of the Effect of Protein Supplementation on Resistance Training-Induced Gains in Muscle Mass and Strength in Healthy Adults. Br. J. Sports Med. 2018, 52, 376-384. [CrossRef] [PubMed]

8. Hoppeler, H. Molecular Networks in Skeletal Muscle Plasticity. J. Exp. Biol. 2016, 219, 205-213. [CrossRef] [PubMed]

9. Jäger, R.; Kerksick, C.M.; Campbell, B.I.; Cribb, P.J.; Wells, S.D.; Skwiat, T.M.; Purpura, M.; Ziegenfuss, T.N.; Ferrando, A.A.; Arent, S.M.; et al. International Society of Sports Nutrition Position Stand: Protein and Exercise. J. Int. Soc. Sports Nutr. 2017, 14, 20. [CrossRef] [PubMed]

10. Zdzieblik, D.; Oesser, S.; Baumstark, M.W.; Gollhofer, A.; König, D. Collagen Peptide Supplementation in Combination with Resistance Training Improves Body Composition and Increases Muscle Strength in Elderly Sarcopenic Men: A Randomised Controlled Trial. Br. J. Nutr. 2015, 114, 1237-1245. [CrossRef]

11. Feng, M.; Betti, M. Transepithelial Transport Efficiency of Bovine Collagen Hydrolysates in a Human Caco-2 Cell Line Model. Food Chem. 2017, 224, 242-250. [CrossRef]

12. Taga, Y.; Kusubata, M.; Ogawa-Goto, K.; Hattori, S. Highly Accurate Quantification of Hydroxyproline-Containing Peptides in Blood Using a Protease Digest of Stable Isotope-Labeled Collagen. J. Agric. Food Chem. 2014, 62, 12096-12102. [CrossRef] [PubMed]

13. Taga, Y.; Kusubata, M.; Ogawa-Goto, K.; Hattori, S. Efficient Absorption of X-Hydroxyproline (Hyp)-Gly after Oral Administration of a Novel Gelatin Hydrolysate Prepared Using Ginger Protease. J. Agric. Food Chem. 2016, 64, 2962-2970. [CrossRef] [PubMed]

14. Wang, L.; Wang, Q.; Liang, Q.; He, Y.; Wang, Z.; He, S.; Xu, J.; Ma, H. Determination of Bioavailability and Identification of Collagen Peptide in Blood after Oral Ingestion of Gelatin. J. Sci. Food Agric. 2015, 95, 2712-2717. [CrossRef]

15. Schunck, M.; Oesser, S. Specific Collagen Peptides Benefit the Biosynthesis of Matrix Molecules of Tendons and Ligaments. J. Int Soc. Sports Nutr. 2013, 10, P23. [CrossRef]

16. Oesser, S.; Seifert, J. Stimulation of Type II Collagen Biosynthesis and Secretion in Bovine Chondrocytes Cultured with Degraded Collagen. Cell Tissue Res. 2003, 311, 393-399. [CrossRef]

17. McAlindon, T.E.; Nuite, M.; Krishnan, N.; Ruthazer, R.; Price, L.L.; Burstein, D.; Griffith, J.; Flechsenhar, K. Change in Knee Osteoarthritis Cartilage Detected by Delayed Gadolinium Enhanced Magnetic Resonance Imaging Following Treatment with Collagen Hydrolysate: A Pilot Randomized Controlled Trial. Osteoarthr. Cartil. 2011, 19, 399-405. [CrossRef] [PubMed]

18. Clark, K.L.; Sebastianelli, W.; Flechsenhar, K.R.; Aukermann, D.F.; Meza, F.; Millard, R.L.; Deitch, J.R.; Sherbondy, P.S.; Albert, A. 24-Week Study on the Use of Collagen Hydrolysate as a Dietary Supplement in Athletes with Activity-Related Joint Pain. Curr. Med. Res. Opin. 2008, 24, 1485-1496. [CrossRef] [PubMed]

19. Zdzieblik, D.; Oesser, S.; Gollhofer, A.; König, D. Improvement of Activity-Related Knee Joint Discomfort Following Supplementation of Specific Collagen Peptides. Appl. Physiol. Nutr. Metab. 2017, 1-8. [CrossRef]

20. Zdzieblik, D.; Brame, J.; Oesser, S.; Gollhofer, A.; König, D. The Influence of Specific Bioactive Collagen Peptides on Knee Joint Discomfort in Young Physically Active Adults: A Randomized Controlled Trial. Nutrients 2021, 13, 523. [CrossRef]

21. Praet, S.F.E.; Purdam, C.R.; Welvaert, M.; Vlahovich, N.; Lovell, G.; Burke, L.M.; Gaida, J.E.; Manzanero, S.; Hughes, D.; Waddington, G. Oral Supplementation of Specific Collagen Peptides Combined with Calf-Strengthening Exercises Enhances Function and Reduces Pain in Achilles Tendinopathy Patients. Nutrients 2019, 11, 76. [CrossRef]

22. Baar, K. Stress Relaxation and Targeted Nutrition to Treat Patellar Tendinopathy. Int. J. Sport Nutr. Exerc. Metab. 2019, 29 , 453-457. [CrossRef]

23. Dressler, P.; Gehring, D.; Zdzieblik, D.; Oesser, S.; Gollhofer, A.; König, D. Improvement of Functional Ankle Properties Following Supplementation with Specific Collagen Peptides in Athletes with Chronic Ankle Instability. J. Sports Sci. Med. 2018, 17, 298-304. [CrossRef]

24. Sun, K.; Wu, Z.; Ji, Y.; Wu, G. Glycine Regulates Protein Turnover by Activating Protein Kinase B/Mammalian Target of Rapamycin and by Inhibiting MuRF1 and Atrogin-1 Gene Expression in C2C12 Myoblasts. J. Nutr. 2016, 146, 2461-2467. [CrossRef] 
25. Kitakaze, T.; Sakamoto, T.; Kitano, T.; Inoue, N.; Sugihara, F.; Harada, N.; Yamaji, R. The Collagen Derived Dipeptide Hydroxyprolyl-Glycine Promotes C2C12 Myoblast Differentiation and Myotube Hypertrophy. Biochem. Biophys. Res. Commun. 2016, 478, 1292-1297. [CrossRef]

26. Liu, Y.; Wang, X.; Wu, H.; Chen, S.; Zhu, H.; Zhang, J.; Hou, Y.; Hu, C.-A.A.; Zhang, G. Glycine Enhances Muscle Protein Mass Associated with Maintaining Akt-MTOR-FOXO1 Signaling and Suppressing TLR4 and NOD2 Signaling in Piglets Challenged with LPS. Am. J. Physiol. Regul. Integr. Comp. Physiol. 2016, 311, R365-R373. [CrossRef] [PubMed]

27. Rolland, Y.; Czerwinski, S.; Abellan Van Kan, G.; Morley, J.E.; Cesari, M.; Onder, G.; Woo, J.; Baumgartner, R.; Pillard, F.; Boirie, Y.; et al. Sarcopenia: Its Assessment, Etiology, Pathogenesis, Consequences and Future Perspectives. J. Nutr. Health Aging 2008, 12, 433-450. [CrossRef] [PubMed]

28. Aagaard, P.; Suetta, C.; Caserotti, P.; Magnusson, S.P.; Kjaer, M. Role of the Nervous System in Sarcopenia and Muscle Atrophy with Aging: Strength Training as a Countermeasure. Scand. J. Med. Sci. Sports 2010, 20, 49-64. [CrossRef] [PubMed]

29. Waters, D.L.; Baumgartner, R.N.; Garry, P.J.; Vellas, B. Advantages of Dietary, Exercise-Related, and Therapeutic Interventions to Prevent and Treat Sarcopenia in Adult Patients: An Update. Clin. Interv. Aging 2010, 5, 259-270. [CrossRef]

30. Riebe, D.; Franklin, B.A.; Thompson, P.D.; Garber, C.E.; Whitfield, G.P.; Magal, M.; Pescatello, L.S. Updating ACSM's Recommendations for Exercise Preparticipation Health Screening. Med. Sci. Sports Exerc. 2015, 47, 2473-2479. [CrossRef] [PubMed]

31. Urbaniak, G.C.; Plous, S. Research Randomizer (Version 4.0). Available online: https://www.randomizer.org/about (accessed on 29 July 2014).

32. Claxton, A.J.; Cramer, J.; Pierce, C. A Systematic Review of the Associations between Dose Regimens and Medication Compliance. Clin. Ther. 2001, 23, 1296-1310. [CrossRef]

33. Kim, J.; Wang, Z.; Heymsfield, S.B.; Baumgartner, R.N.; Gallagher, D. Total-Body Skeletal Muscle Mass: Estimation by a New Dual-Energy X-Ray Absorptiometry Method. Am. J. Clin. Nutr. 2002, 76, 378-383. [CrossRef] [PubMed]

34. Cermak, N.M.; Res, P.T.; de Groot, L.C.P.G.M.; Saris, W.H.M.; van Loon, L.J.C. Protein Supplementation Augments the Adaptive Response of Skeletal Muscle to Resistance-Type Exercise Training: A Meta-Analysis. Am. J. Clin. Nutr. 2012, 96, 1454-1464. [CrossRef] [PubMed]

35. Finger, D.; Goltz, F.R.; Umpierre, D.; Meyer, E.; Rosa, L.H.T.; Schneider, C.D. Effects of Protein Supplementation in Older Adults Undergoing Resistance Training: A Systematic Review and Meta-Analysis. Sports Med. 2015, 45, 245-255. [CrossRef]

36. Phillips, S.M.; Tang, J.E.; Moore, D.R. The Role of Milk- and Soy-Based Protein in Support of Muscle Protein Synthesis and Muscle Protein Accretion in Young and Elderly Persons. J. Am. Coll. Nutr. 2009, 28, 343-354. [CrossRef]

37. Kirmse, M.; Oertzen-Hagemann, V.; de Marées, M.; Bloch, W.; Platen, P. Prolonged Collagen Peptide Supplementation and Resistance Exercise Training Affects Body Composition in Recreationally Active Men. Nutrients 2019, 11, 1154. [CrossRef] [PubMed]

38. Rindom, E.; Nielsen, M.H.; Kececi, K.; Jensen, M.E.; Vissing, K.; Farup, J. Effect of Protein Quality on Recovery after Intense Resistance Training. Eur. J. Appl. Physiol. 2016, 116, 2225-2236. [CrossRef]

39. Oertzen-Hagemann, V.; Kirmse, M.; Eggers, B.; Pfeiffer, K.; Marcus, K.; de Marées, M.; Platen, P. Effects of 12 Weeks of Hypertrophy Resistance Exercise Training Combined with Collagen Peptide Supplementation on the Skeletal Muscle Proteome in Recreationally Active Men. Nutrients 2019, 11, 1072. [CrossRef] [PubMed]

40. Zdzieblik, D.; Oesser, S.; Dressler, P.; Gollhofer, A.; König, D. Effect of Specific Collagen Peptides with Various Dosages on Body Composition in Untrained Men. Proc. Nutr. Soc. 2017, 76. [CrossRef]

41. Hamaia, S.; Farndale, R.W. Integrin Recognition Motifs in the Human Collagens. Adv. Exp. Med. Biol. 2014, 819, 127-142. [CrossRef] [PubMed]

42. Gullberg, D.E.; Lundgren-Akerlund, E. Collagen-Binding I Domain Integrins-What Do They Do? Prog. Histochem. Cytochem. 2002, 37, 3-54. [CrossRef]

43. Turrina, A.; Martínez-González, M.A.; Stecco, C. The Muscular Force Transmission System: Role of the Intramuscular Connective Tissue. J. Bodyw. Mov. Ther. 2013, 17, 95-102. [CrossRef]

44. Purslow, P.P. The Structure and Functional Significance of Variations in the Connective Tissue within Muscle. Comp. Biochem. Physiol. Part A Mol. Integr. Physiol. 2002, 133, 947-966. [CrossRef]

45. Kjaer, M.; Jørgensen, N.R.; Heinemeier, K.; Magnusson, S.P. Exercise and Regulation of Bone and Collagen Tissue Biology. Prog. Mol. Biol. Transl. Sci. 2015, 135, 259-291. [CrossRef]

46. Gattazzo, F.; Urciuolo, A.; Bonaldo, P. Extracellular Matrix: A Dynamic Microenvironment for Stem Cell Niche. Biochim. Biophys. Acta 2014, 1840, 2506-2519. [CrossRef] [PubMed]

47. Fry, C.S.; Kirby, T.J.; Kosmac, K.; McCarthy, J.J.; Peterson, C.A. Myogenic Progenitor Cells Control Extracellular Matrix Production by Fibroblasts during Skeletal Muscle Hypertrophy. Cell Stem Cell 2017, 20, 56-69. [CrossRef] [PubMed]

48. Weh, L.; Petau, C. Änderung Der Gewebeeigenschaften Durch Gelatineeinnahme-Eine Biomechanische in Vivo-Pilotstudie. Extr. Orthop. 2001, 4, 12-15.

49. Toselli, S.; Badicu, G.; Bragonzoni, L.; Spiga, F.; Mazzuca, P.; Campa, F. Comparison of the Effect of Different Resistance Training Frequencies on Phase Angle and Handgrip Strength in Obese Women: A Randomized Controlled Trial. Int. J. Environ. Res. Public Health 2020, 17, 1163. [CrossRef] [PubMed]

50. Klop, B.; Elte, J.W.F.; Castro Cabezas, M. Dyslipidemia in Obesity: Mechanisms and Potential Targets. Nutrients 2013, 5, 1218-1240. [CrossRef] [PubMed] 
51. Mekary, R.A.; Grøntved, A.; Despres, J.-P.; De Moura, L.P.; Asgarzadeh, M.; Willett, W.C.; Rimm, E.B.; Giovannucci, E.; Hu, F.B. Weight Training, Aerobic Physical Activities, and Long-Term Waist Circumference Change in Men. Obesity 2015, $23,461-467$. [CrossRef] [PubMed]

52. Dos Santos, L.; Ribeiro, A.S.; Nunes, J.P.; Tomeleri, C.M.; Nabuco, H.C.G.; Nascimento, M.A.; Sugihara Junior, P.; Fernandes, R.R.; Campa, F.; Toselli, S.; et al. Effects of Pyramid Resistance-Training System with Different Repetition Zones on Cardiovascular Risk Factors in Older Women: A Randomized Controlled Trial. Int. J. Environ. Res. Public Health 2020, 17, 6115. [CrossRef] [PubMed]

53. Faienza, M.F.; Lassandro, G.; Chiarito, M.; Valente, F.; Ciaccia, L.; Giordano, P. How Physical Activity across the Lifespan Can Reduce the Impact of Bone Ageing: A Literature Review. Int. J. Environ. Res. Public Health 2020, 17, 1862. [CrossRef] [PubMed]

54. Guadalupe-Grau, A.; Fuentes, T.; Guerra, B.; Calbet, J.A.L. Exercise and Bone Mass in Adults. Sports Med. 2009, 39, 439-468. [CrossRef]

55. Hall, K.D.; Sacks, G.; Chandramohan, D.; Chow, C.C.; Wang, Y.C.; Gortmaker, S.L.; Swinburn, B.A. Quantification of the Effect of Energy Imbalance on Bodyweight. Lancet 2011, 378. [CrossRef]

56. National Research Council (US). Recommended Dietary Allowances, 10th ed.; National Academies Press: Washington, DC, USA, 1989.

57. Heseker, H.; Heseker, B. Die Nährwerttabelle; Umschau: Neustadt an der Weinstraße, Germany, 2010.

58. Mendez, M.A.; Popkin, B.M.; Buckland, G.; Schroder, H.; Amiano, P.; Barricarte, A.; Huerta, J.-M.; Quirós, J.R.; Sánchez, M.-J.; González, C.A. Alternative Methods of Accounting for Underreporting and Overreporting When Measuring Dietary IntakeObesity Relations. Am. J. Epidemiol. 2011, 173, 448-458. [CrossRef] 